\title{
Deconstructable flush end plate beam-to-column composite joints: component-based modelling
}

\author{
M. A. Bradford*, A. Ataei and X. Liu \\ Centre for Infrastructure Engineering and Safety, UNSW Sydney, Australia \\ *corresponding author, e-mail address: m.bradford@unsw.edu.au
}

\begin{abstract}
Within a paradigm of designing building structures for their end-of-life deconstruction, this paper addresses flush end plate beam-to-column composite joints that may be disassembled and reused elsewhere. The joints consist of steel beams bolted to steel columns, and these are made composite over the joint with precast concrete slabs attached to the top flange of the steel beams with post-tensioned high strength bolted shear connectors installed in clearance holes. Joints of this type experience partial shear connection, and accordingly their design needs to incorporate this effect. Experimental work reported elsewhere by the authors shows that a structural system of this type may indeed be deconstructed, even when loaded beyond the serviceability limit state, and that the momentrotation response is both robust and ductile. A numerical modelling procedure using ABAQUS software is introduced in the paper, and the results of this are used identify the parameters most influential in the structural response, and to propose equations for the initial stiffness, moment capacity and rotation capacity of a joint. These equations are consistent with the component-based representation of the Eurocode 4 and Australian AS2327 composite structures standard.
\end{abstract}

Keywords: Component method; composite joint; deconstructable; friction grip; FEM.

\section{Introduction}

The favourable attributes of constructing steel-concrete composite framed buildings for deconstruction and material reuse are manyfold. It has been shown that by using precast concrete slabs with post-installed tensioned friction-grip bolted shear connectors (PFGBSCs) to connect them to steel beams allows for robust composite action, as well as for deconstruction by unbolting the shear connectors at the end of the structural life of the building [1-5]. In regions of hogging bending at a column (Fig. 1), the use of flush end plate bolted connections also allows for unbolting to expedite deconstruction [6-8].

While experimental tests have provided both proof of concept and data bases for calibrating associated numerical models of such framed structures [8], structural design guidance is needed in codified formats for engineering practitioners. A popular technique used in the Eurocodes EC3 [9] and EC4 [10] is the component-based method [11], which provides a good balance of accuracy and simplicity. The aim of the current paper is to develop such a model for deconstructable flush end plate beamto-column composite joints, based on a numerical model validated by experiments. The equations developed fit well within the design procedures of EC4 [10] and the Australian AS2327 [12].
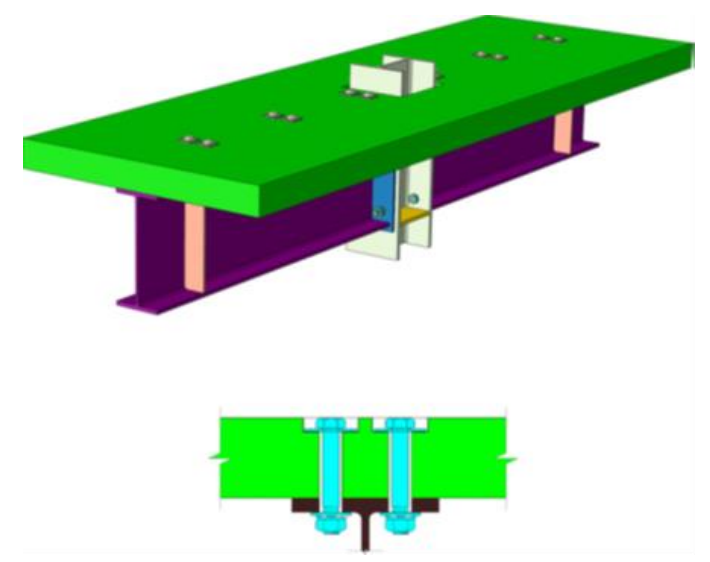

Fig. 1. Deconstructable flush end plate composite joint. 


\section{Computational modelling}

The structural behaviour of full-scale beamto-column joints with deconstructable PFGBSCs and precast concrete slabs subjected to static loading has been investigated with a threedimensional FE model [8] using ABAQUS/CAE software [13], and the various components of the joint are shown in Fig. 2. Material and geometrical non-linearities as well as the nonlinearity associated with contacts/interfaces were incorporated in the model. Because of the symmetry of the specimens and loading, only half of each joint was considered as illustrated in Fig. 3. The procedures for the modelling, material constitutive relationships, constraints, boundary conditions, meshing, contacts, and load application are presented in detail in [8], as well as validation of the model. Accordingly, the current paper focuses only on using the model in [8] to provide the data for validating the component-based approach.

Based on the parametric study used for the component model, the most influential parameters that influence the behaviour of the deconstructable composite joints were identified. A $67 \%$ shear connection ratio, $0.70 \%$ reinforcing ratio, 460UB82.1 steel beam, 250 UC89.5 steel column, $120 \mathrm{~mm}$ precast concrete slab, $10 \mathrm{~mm}$ flush end plate and Grade 10.9 M24 bolt were adopted for the standard joint considered in the parametric study, but each respective property was varied.

Shear connection ratios (SCRs) of $34 \%, 54 \%$, $67 \%, 101 \%, 108 \%, 162 \%, 170 \%$ and $162 \%$ were considered to investigate their effect at the interface between the precast concrete slab and the steel beam. The ratio of the shear connection between the steel beam and precast concrete slab was obtained by changing the number and size of the bolt shear connectors and their spacing along the composite beam length. To gain insight in to the effect of the spacing of the bolted shear connectors on the behaviour of composite joints with PFGBSCs and a precast concrete slab, three different spacings of the shear connectors $(275,550$ and $1100 \mathrm{~mm})$ were considered. Different reinforcement ratios of $0.36 \%, 0.43 \%, 0.51 \%, 0.60 \%, 0.70 \%, 0.80 \%$, $0.91 \%$ and $1.03 \%$ were used to investigate their effect on the moment-rotation responses. The effect of the bolt size was determined using nine diameters: 12, 14, 16, 18, 20, 22, 24, 26, 28 and $30 \mathrm{~mm}$, which corresponds to respective end plate thickness to bolt diameter ratios $t_{e p} / d_{b}$ of

$0.83,0.71,0.63,0.56,0.50,0.45,0.42,0.38,0.36$ and 0.33. Eleven plate thicknesses: $6,8,10,12$, $14,16,18,20,22,26$ and $30 \mathrm{~mm}$ were used to study the effect of the flush end plate thickness on the behaviour of composite joints with PFGBSCs and a precast concrete slab. Seven different steel grades, ranging from S235 to S960, were chosen to investigate the effect of this property on the behaviour of the composite joints, while seven different precast concrete slab thicknesses: $80,120,160,200,240,280$, $320 \mathrm{~mm}$ were employed to investigate the effect of this parameter on the behaviour of the composite joints. Six different steel column flange thicknesses: 10, 14, 18, 22, 26, 280, 30 $\mathrm{mm}$ were considered in this study in order to investigate their effect on the behaviour of the composite joints.

(b) Steel

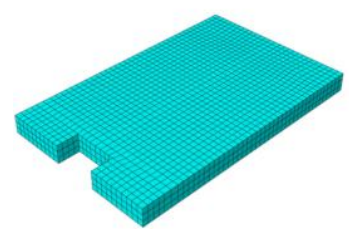

(c) Half slab
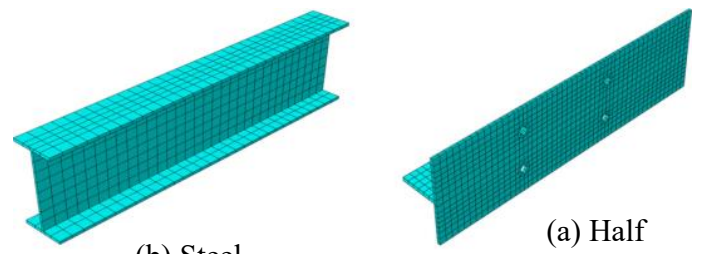

column

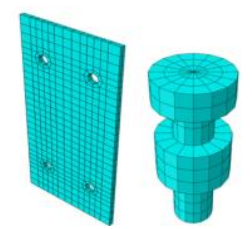

(d) End plate and bolt

Fig. 2. FE mesh of joint components.

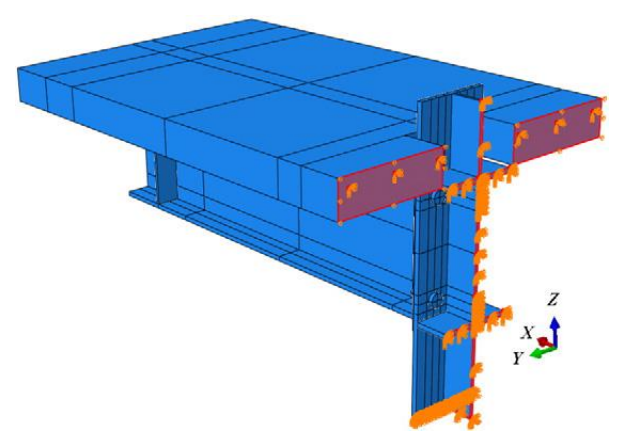

Fig. 3. Half joint considered in FE modelling.

\section{Component-based modelling}

The component-based method provided in EC4 [10] is extended herein to predict the initial stiffness of composite joints having PFGBSCs and a precast concrete slab. In this method, each component of the composite connection is represented by an elastic spring (Fig. 4) and the stiffness of the connection is assessed through 
the assemblage of the components. The rebars, flush end plate, bolts in the tension zone, column flange and column web are the main components contributing to the initial rotational stiffness. An effective stiffness $k_{\text {eff }}$ for a bolt row can be obtained by combining the stiffness of the end plate in bending $k_{3}$, bolts in tension $k_{4}$, column flange in bending $k_{5}$ and column web in tension $k_{6}$, in series. The stiffness coefficients of the column web in compression $k_{1}$ and column web in shear $k_{2}$ are assumed to be infinite due to the stiffened steel column and by the symmetric loading on the connection. The stiffness of the rebars $k_{7}$ is combined with $k_{\text {eff }}$ and a single equivalent stiffness coefficient $k_{e q}$ and its equivalent lever arm $z_{e q}$ is obtained. The initial stiffness of the composite joint can then be written as $S_{j}=E k_{e q} z_{e q}^{2}$ (in $\mathrm{kNmm} / \mathrm{mrad}$ ).

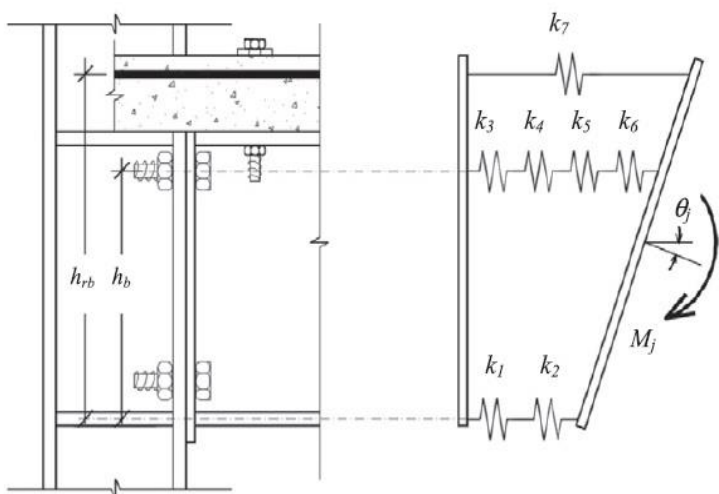

Fig. 3. Initial rotational stiffness model.

The initial stiffness derived from the component-based model developed is compared in Table 1 with the FE results. It can be seen that there is good agreement between these two approaches for most of the models, but a large discrepancy can be seen for a few cases such as those having a high reinforcement ratio. Liew et al. [14] reached similar conclusions after comparing their composite joint test results with those predicted by the component method, as the component-based method provided 26 to $83 \%$ higher initial stiffnesses compared to their test results [14]. Comparisons between the results predicted by Ahmad and Nethercot's model [15] and the component-based method shows that except for some cases, both techniques appear to be appropriate to use for estimating the initial stiffness of a deconstructable composite joint.

Table 1. Initial rotational stiffness predictions.

\begin{tabular}{|c|c|c|c|c|c|c|}
\hline \multirow[t]{2}{*}{ Variable } & \multirow[t]{2}{*}{ Model } & \multirow[t]{2}{*}{ FEM } & \multicolumn{2}{|c|}{$\begin{array}{c}\text { Component } \\
\text { method }\end{array}$} & \multicolumn{2}{|c|}{$\begin{array}{l}\text { Ahmed \& } \\
\text { Nethercot }\end{array}$} \\
\hline & & & $\begin{array}{c}\mathrm{kNm} \\
/ \mathrm{rad}\end{array}$ & ratio & $\underset{\mathrm{kNm}}{\mathrm{kNad}}$ & ratio \\
\hline \multirow{11}{*}{$\begin{array}{l}\text { Reinfor- } \\
\text { cement } \\
\text { ratio }\end{array}$} & 0.36 & 62 & 54 & 0.87 & 51 & 0.82 \\
\hline & 0.43 & 69 & 57 & 0.83 & 56 & 0.81 \\
\hline & 0.51 & 70 & 60 & 0.86 & 62 & 0.89 \\
\hline & 0.60 & 72 & 62 & 0.86 & 65 & 0.90 \\
\hline & 0.70 & 73 & 67 & 0.92 & 66 & 0.90 \\
\hline & 0.80 & 73 & 70 & 0.96 & 83 & 1.14 \\
\hline & 0.91 & 74 & 73 & 0.99 & 91 & 1.23 \\
\hline & 1.03 & 75 & 77 & 1.03 & 99 & 1.32 \\
\hline & 1.16 & 75 & 80 & 1.07 & 107 & 1.43 \\
\hline & 1.29 & 75 & 84 & 1.12 & 115 & 1.53 \\
\hline & 1.43 & 76 & 88 & 1.16 & 124 & 1.63 \\
\hline \multirow{8}{*}{$\begin{array}{l}\text { Shear } \\
\text { connector }\end{array}$} & 2M16 & 46 & 63 & 1.37 & 53 & 1.15 \\
\hline & $2 \mathrm{M} 20$ & 52 & 65 & 1.25 & 55 & 1.06 \\
\hline & 4M16 & 70 & 66 & 0.94 & 66 & 0.94 \\
\hline & $6 \mathrm{M} 16$ & 85 & 80 & 0.94 & 77 & 0.91 \\
\hline & $4 \mathrm{M} 20$ & 72 & 67 & 0.93 & 56 & 0.78 \\
\hline & $6 \mathrm{M} 20$ & 88 & 81 & 0.92 & 78 & 0.89 \\
\hline & $10 \mathrm{M} 16$ & 111 & 97 & 0.87 & 107 & 0.96 \\
\hline & $10 \mathrm{M} 20$ & 114 & 99 & 0.87 & 108 & 0.95 \\
\hline \multirow{7}{*}{$\begin{array}{l}\text { Slab } \\
\text { thickness } \\
(\mathrm{mm})\end{array}$} & 80 & 53 & 61 & 1.15 & 52 & 0.98 \\
\hline & 120 & 73 & 66 & 0.90 & 66 & 0.90 \\
\hline & 160 & 85 & 70 & 0.82 & 67 & 0.79 \\
\hline & 200 & 97 & 75 & 0.77 & 68 & 0.70 \\
\hline & 240 & 121 & 80 & 0.66 & 68 & 0.56 \\
\hline & 280 & 142 & 86 & 0.61 & 68 & 0.48 \\
\hline & 320 & 167 & 91 & 0.54 & 68 & 0.41 \\
\hline \multirow{10}{*}{$\begin{array}{l}\text { Bolt } \\
\text { size } \\
(\mathrm{mm})\end{array}$} & 12 & 58 & 58 & 1.00 & 66 & 1.14 \\
\hline & 14 & 65 & 61 & 0.92 & 66 & 1.02 \\
\hline & 16 & 65 & 63 & 0.97 & 66 & 1.02 \\
\hline & 18 & 66 & 64 & 0.97 & 66 & 1.00 \\
\hline & 20 & 68 & 64 & 0.94 & 66 & 0.97 \\
\hline & 22 & 73 & 65 & 0.89 & 66 & 0.90 \\
\hline & 24 & 73 & 66 & 0.90 & 66 & 0.90 \\
\hline & 26 & 74 & 67 & 0.91 & 66 & 0.89 \\
\hline & 28 & 82 & 67 & 0.82 & 66 & 0.80 \\
\hline & 30 & 97 & 68 & 0.70 & 66 & 0.68 \\
\hline \multirow{11}{*}{$\begin{array}{l}\text { End } \\
\text { plate } \\
\text { thickness } \\
(\mathrm{mm})\end{array}$} & 6 & 27 & 41 & 1.52 & 66 & 2.44 \\
\hline & 8 & 56 & 53 & 0.95 & 66 & 1.18 \\
\hline & 10 & 73 & 67 & 0.92 & 66 & 0.90 \\
\hline & 12 & 93 & 75 & 0.81 & 66 & 0.71 \\
\hline & 14 & 112 & 83 & 0.74 & 66 & 0.59 \\
\hline & 16 & 128 & 89 & 0.70 & 66 & 0.52 \\
\hline & 18 & 146 & 94 & 0.64 & 66 & 0.45 \\
\hline & 20 & 158 & 96 & 0.61 & 66 & 0.42 \\
\hline & 22 & 170 & 97 & 0.57 & 66 & 0.39 \\
\hline & 26 & 185 & 98 & 0.53 & 66 & 0.36 \\
\hline & 30 & 196 & 98 & 0.50 & 66 & 0.34 \\
\hline \multirow{6}{*}{$\begin{array}{l}\text { Column } \\
\text { flange } \\
\text { thickness } \\
(\mathrm{mm})\end{array}$} & 10 & 36 & 55 & 1.53 & 66 & 1.93 \\
\hline & 14 & 53 & 63 & 1.19 & 66 & 1.25 \\
\hline & 18 & 73 & 66 & 0.90 & 66 & 0.90 \\
\hline & 22 & 77 & 67 & 0.87 & 66 & 0.86 \\
\hline & 26 & 83 & 68 & 0.82 & 66 & 0.80 \\
\hline & 30 & 86 & 68 & 0.79 & 66 & 0.77 \\
\hline Ave & & & & 0.90 & & 0.93 \\
\hline Stan & tion & & & 0.22 & & 0.38 \\
\hline
\end{tabular}

The moment capacities of composite joints with PFGBSCs and precast concrete slabs can be calculated using the concept of rigid plastic analysis. Anderson and Najafi [15] proposed an approach (Fig. 4) using this technique for the calculation of the moment capacity of traditional composite connections, and their model is extended herein for composite joints with PFGBSCs and precast concrete slabs. The bending strength of a composite joint can be determined from

$M_{j}=F_{r b}\left(h_{r b}-0.5 t_{f b}\right)+F_{b}\left(h_{b}-0.5 t_{f b}\right)$

if $F_{r b}+F_{b} \leq F_{f b}$, and from 


$$
\begin{aligned}
& M_{j}=F_{r b}\left(h_{r b}-0.5 t_{f b}\right)+F_{b}\left(h_{b}-0.5 t_{f b}\right) \\
& -\left(F_{r b}+F_{b}-F_{f b}\right) \cdot\left(0.5 y_{c}+0.5 t_{f b}\right)
\end{aligned}
$$

if $F_{r b}+F_{b}>F_{f b}$, in which $F_{r b}$ is the tensile strength of the longitudinal rebars, $F_{b l}$ the tensile force in the bolts at the top row, $F_{f b c}$ the resistance force in the bottom flange of the steel beam, $h_{r b}$ the distance between the centroid of the reinforcing bars and the centroid of the steel beam bottom flange, $h_{b}$ the distance between the centroid of the top row of bolts and the centroid of the steel beam bottom flange and $t_{f b}$ the thickness of the steel beam bottom flange (Fig. 4). In addition, $y_{c}$ is the depth of web in compression, being obtained from

$y_{c}=\frac{F_{r b}+F_{b}-F_{f b}}{t_{f b} f_{y b}}$.

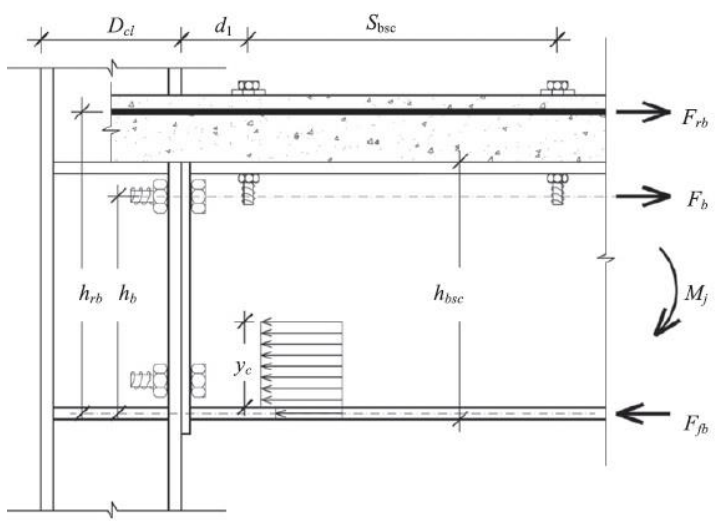

Fig. 4. Moment capacity model.

The moment capacity determined from this method is compared with the FE results in Table 2. It can be seen that good agreement between these two approaches is demonstrated for most of the models. However, there is a discrepancy for a few cases, such as those with very high reinforcement ratios or with very low degrees of shear connection. This is because the design method is not applicable to composite joints with an overly-low degree of shear connection, as its failure governed by fracture of shear connectors.

In order to incorporate the effects of partial shear connection in this method, the strength of the longitudinal reinforcing bars located in the precast concrete slab was limited by the shear strength of the bolted shear connectors. Because of this, based on the experimental results achieved by Ataei et al. [4-7], when the yield strength of the reinforcement $\left(F_{r b}\right)$ is 1.5 times that of the shear strength of the bolted shear connectors $\left(F_{b s c}\right), F_{r b}$ can be obtained from

$$
F_{r b}=1.5 F_{b s c} \text {. }
$$

When the effect of partial shear connection is taken into calculation of the moment capacity of a composite joint with PFGBSCs and a precast concrete slab, the analytical model provides much closer results (the values in brackets) to the

\begin{tabular}{|c|c|c|c|c|}
\hline \multirow[t]{2}{*}{ Variable } & \multirow[t]{2}{*}{ Model } & FEM & \multicolumn{2}{|c|}{ Anderson \& Najafi } \\
\hline & & \multicolumn{2}{|c|}{$\mathrm{kNm} / \mathrm{rad}$} & ratio \\
\hline \multirow{11}{*}{$\begin{array}{l}\text { Reinforcement } \\
\text { ratio }\end{array}$} & 0.36 & 340 & 383 & 1.13 \\
\hline & 0.43 & 377 & 412 & 1.09 \\
\hline & 0.51 & 416 & 444 & 1.07 \\
\hline & 0.60 & 456 & 479 & 1.05 \\
\hline & 0.70 & 540 & 517 & 0.96 \\
\hline & 0.80 & 589 & 558 & 0.95 \\
\hline & 0.91 & 602 & 601 & 1.00 \\
\hline & 1.03 & 573 & 647 & 1.13 \\
\hline & 1.16 & 548 & $696(654)$ & $1.27(1.19)$ \\
\hline & 1.29 & 548 & $747(654)$ & $1.36(1.19)$ \\
\hline & 1.43 & 548 & $802(654)$ & $1.46(1.19)$ \\
\hline \multirow{8}{*}{$\begin{array}{l}\text { Shear } \\
\text { connector }\end{array}$} & 2M16 & 422 & $517(449)$ & $1.23(1.06)$ \\
\hline & $2 \mathrm{M} 20$ & 530 & 517 & 0.98 \\
\hline & $4 \mathrm{M} 16$ & 529 & 517 & 0.98 \\
\hline & $6 \mathrm{M} 16$ & 506 & 517 & 1.02 \\
\hline & 4M20 & 521 & 517 & 0.99 \\
\hline & $6 \mathrm{M} 20$ & 486 & 517 & 1.06 \\
\hline & $10 \mathrm{M} 16$ & 479 & 517 & 1.08 \\
\hline & $10 \mathrm{M} 20$ & 479 & 517 & 1.08 \\
\hline \multirow{7}{*}{$\begin{array}{l}\text { Slab } \\
\text { thickness } \\
(\mathrm{mm})\end{array}$} & 80 & 526 & 497 & 0.94 \\
\hline & 120 & 540 & 517 & 0.96 \\
\hline & 160 & 559 & 537 & 0.96 \\
\hline & 200 & 577 & 558 & 0.97 \\
\hline & 240 & 598 & 578 & 0.97 \\
\hline & 280 & 616 & 598 & 0.97 \\
\hline & 320 & 635 & 619 & 0.97 \\
\hline \multirow{10}{*}{$\begin{array}{l}\text { Bolt size } \\
(\mathrm{mm})\end{array}$} & 12 & 345 & 339 & 0.98 \\
\hline & 14 & 404 & 365 & 0.90 \\
\hline & 16 & 436 & 395 & 0.91 \\
\hline & 18 & 465 & 412 & 0.89 \\
\hline & 20 & 492 & 442 & 0.90 \\
\hline & 22 & 520 & 483 & 0.93 \\
\hline & 24 & 540 & 517 & 0.96 \\
\hline & 26 & 548 & 559 & 1.02 \\
\hline & 28 & 556 & 611 & 1.10 \\
\hline & 30 & 562 & 620 & 1.10 \\
\hline \multirow{11}{*}{$\begin{array}{l}\text { End plate } \\
\text { thickness } \\
(\mathrm{mm})\end{array}$} & 6 & 480 & 517 & 1.08 \\
\hline & 8 & 507 & 517 & 1.02 \\
\hline & 10 & 532 & 517 & 0.97 \\
\hline & 12 & 544 & 517 & 0.95 \\
\hline & 14 & 568 & 517 & 0.91 \\
\hline & 16 & 596 & 517 & 0.87 \\
\hline & 18 & 620 & 517 & 0.83 \\
\hline & 20 & 642 & 517 & 0.81 \\
\hline & 22 & 658 & 517 & 0.79 \\
\hline & 26 & 665 & 517 & 0.78 \\
\hline & 30 & 665 & 517 & 0.78 \\
\hline \multirow{6}{*}{$\begin{array}{l}\text { Column } \\
\text { flange } \\
\text { thickness } \\
(\mathrm{mm})\end{array}$} & 10 & 500 & 517 & 1.03 \\
\hline & 14 & 527 & 517 & 0.98 \\
\hline & 18 & 544 & 517 & 0.95 \\
\hline & 22 & 546 & 517 & 0.95 \\
\hline & 26 & 546 & 517 & 0.95 \\
\hline & 30 & 546 & 517 & 0.95 \\
\hline \multirow{2}{*}{\multicolumn{2}{|c|}{$\begin{array}{l}\text { Average } \\
\text { Standard deviation }\end{array}$}} & & & $1.00(0.95)$ \\
\hline & & & & $0.13(0.10)$ \\
\hline
\end{tabular}
FE predictions.

Table 2. Moment capacity predictions.

The assessment of the ductility of a composite connection is conducted by determining its rotation capacity. In addition, according to guidance given in EC4, if the minimum rotation capacity of a composite joint 
is larger than $30 \mathrm{mrad}$, the joint is deemed to be ductile and plastic analysis and design are permitted. Therefore, calculation of the rotation capacity with sufficient accuracy is needed.

Ahmad and Nethercot [16] proposed a model for the rotation capacity of a connection based on the deformation of the reinforcement and the top row bolts and the slip at the interface between the concrete slab and steel beam, being written as

$\theta_{j}=\frac{\delta_{r b}}{h_{r b}-y_{c}}+\frac{\delta_{b}}{h_{b}-y_{c}}+\frac{s}{D_{b}-y_{c}}$,

where $\delta_{r b}$ is the elongation of the longitudinal reinforcing bars, $\delta_{b}$ the extension of the top row of bolts and $s$ the final slip at the interface between the steel beam and concrete slab. These can be calculated from

$\delta_{r b}=0.01\left(\frac{D_{c l}}{2}+d_{1}+s_{b s c}\right), \delta_{b}=\frac{F_{b}}{K_{b}}, s=\frac{F_{r}}{K_{b s c}}$

where $D_{c l}$ is the depth of the steel column, $D_{b}$ the depth of the steel beam, $d_{1}$ the distance between the column face and the first row of the shear bolts and $s_{b s c}$ the distance between the first row and the second rows of the shear bolts. The stiffness of the top row of bolts $\left(K_{b}\right)$ can be taken as $K_{b}=155 \mathrm{kN} / \mathrm{mm}$. The stiffness of the bolt shear connectors $\left(K_{b s c}\right)$ can be taken as $K_{b s c}=10 n$ $\mathrm{kN} / \mathrm{mm}$ according to the results observed from the tests conducted by Ataei et al. [4,5], where $n$ is the number of bolt shear connectors present in the shear span.

The rotation capacities determined from this model are compared with the FE results in Table 3. Good agreement between these two approaches is observable for most of the models, but there is a large discrepancy for a few cases such as those with very high reinforcement ratios or with high degrees of shear connection. This may be because fracture of the bolt in the connection zone, fracture of the flush end plate and the effect of the degree of shear connection are not considered in Ahmad and Nethercot's model.

So as to incorporate the effect of partial shear connection in this method, the strength of the longitudinal reinforcing bars located in the precast concrete slab was limited by the shear strength of the bolted shear connectors. Accordingly, based on the experimental results obtained by Ataei et al. [4], $\delta_{r b}=0$ if $F_{b s c} \leq$ $0.67 F_{r b}$. Table 3 shows that when the effect of partial shear connection is taken into account, the analytical model can provide closer results (values in brackets) compared to the $\mathrm{FE}$ predictions.

Table 3. Moment capacity predictions.

\begin{tabular}{|c|c|c|c|c|}
\hline \multirow[t]{2}{*}{ Variable } & \multirow[t]{2}{*}{ Model } & FEM & \multicolumn{2}{|c|}{ Ahmed \& Nethercot } \\
\hline & & \multicolumn{2}{|c|}{$\operatorname{mrad}$} & ratio \\
\hline \multirow{11}{*}{$\begin{array}{l}\text { Reinforcement } \\
\text { ratio }\end{array}$} & 0.36 & 31 & 39 & 1.26 \\
\hline & 0.43 & 35 & 42 & 1.20 \\
\hline & 0.51 & 39 & 45 & 1.15 \\
\hline & 0.60 & 42 & 48 & 1.14 \\
\hline & 0.70 & 57 & 53 & 0.93 \\
\hline & 0.80 & 58 & $56(63)$ & $0.97(0.91)$ \\
\hline & 0.91 & 60 & $61(53)$ & $1.02(0.91)$ \\
\hline & 1.03 & 38 & $66(39)$ & $1.74(0.91)$ \\
\hline & 1.16 & 32 & $71(39)$ & $2.22(0.91)$ \\
\hline & 1.29 & 32 & $76(39)$ & $2.38(0.91)$ \\
\hline & 1.43 & 32 & $82(39)$ & $2.56(0.91)$ \\
\hline \multirow{8}{*}{$\begin{array}{l}\text { Shear } \\
\text { connector }\end{array}$} & $2 \mathrm{M} 16$ & 31 & $53(40)$ & $1.71(1.29)$ \\
\hline & $2 \mathrm{M} 20$ & 62 & 53 & 0.85 \\
\hline & 4M16 & 52 & 53 & 1.02 \\
\hline & $6 \mathrm{M} 16$ & 45 & 44 & 0.98 \\
\hline & $4 \mathrm{M} 20$ & 50 & 44 & 0.88 \\
\hline & $6 \mathrm{M} 20$ & 31 & 38 & 1.23 \\
\hline & $10 \mathrm{M} 16$ & 28 & $36(32)$ & $1.29(1.14)$ \\
\hline & $10 \mathrm{M} 20$ & 28 & $33(28)$ & $1.18(1.00)$ \\
\hline \multirow{7}{*}{$\begin{array}{l}\text { Slab } \\
\text { thickness } \\
(\mathrm{mm})\end{array}$} & 80 & 63 & 55 & 0.87 \\
\hline & 120 & 57 & 53 & 0.93 \\
\hline & 160 & 55 & 52 & 0.95 \\
\hline & 200 & 52 & 52 & 1.00 \\
\hline & 240 & 49 & 51 & 1.04 \\
\hline & 280 & 46 & 50 & 1.09 \\
\hline & 320 & 44 & 50 & 1.14 \\
\hline \multirow{10}{*}{$\begin{array}{l}\text { Bolt size } \\
(\mathrm{mm})\end{array}$} & 12 & 22 & 46 & 2.09 \\
\hline & 14 & 27 & 47 & 1.74 \\
\hline & 16 & 38 & 48 & 1.26 \\
\hline & 18 & 43 & 49 & 1.14 \\
\hline & 20 & 44 & 50 & 1.14 \\
\hline & 22 & 51 & 52 & 1.02 \\
\hline & 24 & 57 & 53 & 0.93 \\
\hline & 26 & 56 & 55 & 0.98 \\
\hline & 28 & 58 & 58 & 1.00 \\
\hline & 30 & 56 & 60 & 1.07 \\
\hline \multirow{11}{*}{$\begin{array}{l}\text { End plate } \\
\text { thickness } \\
(\mathrm{mm})\end{array}$} & 6 & 49 & 53 & 1.08 \\
\hline & 8 & 49 & 53 & 1.08 \\
\hline & 10 & 58 & 53 & 0.91 \\
\hline & 12 & 55 & 53 & 0.96 \\
\hline & 14 & 53 & 53 & 1.00 \\
\hline & 16 & 55 & 53 & 0.96 \\
\hline & 18 & 54 & 53 & 0.98 \\
\hline & 20 & 51 & 53 & 1.04 \\
\hline & 22 & 48 & 53 & 1.10 \\
\hline & 26 & 38 & 53 & 1.39 \\
\hline & 30 & 36 & 53 & 1.47 \\
\hline \multirow{6}{*}{$\begin{array}{l}\text { Column } \\
\text { flange } \\
\text { thickness } \\
(\mathrm{mm})\end{array}$} & 10 & 62 & 53 & 0.85 \\
\hline & 14 & 60 & 53 & 0.88 \\
\hline & 18 & 59 & 53 & 0.90 \\
\hline & 22 & 58 & 53 & 0.91 \\
\hline & 26 & 57 & 53 & 0.93 \\
\hline & 30 & 57 & 53 & 0.93 \\
\hline \multirow{2}{*}{\multicolumn{2}{|c|}{$\begin{array}{l}\text { Average } \\
\text { Standard deviation }\end{array}$}} & & & $1.18(1.09)$ \\
\hline & & & & $0.39(0.21)$ \\
\hline
\end{tabular}

\section{Conclusions}

This paper has used the methodology of a FE modelling reported elsewhere by the authors to assess a proposed component-based technique for designing deconstructable flush end plate beam-to-column composite joints. The numerical procedure is underpinned by ABAQUS software and its validity was also confirmed elsewhere by comparisons with test results. The FE procedure allows for a 
substantial combination of parameters over a wide range of those met in practice.

It was shown that prescriptive models available in the literature and augmented appropriately provide a good balance of simplicity and accuracy. These models and their mathematical representation are consistent with techniques already used in codes of practice.

\section{Acknowledgement}

The work in this paper was supported by the Australian Research Council through an Australian Laureate Fellowship (FL100100063) and a Discovery Project (DP150100446) awarded to the first author. This support is gratefully acknowledged.

\section{References}

[1] Bradford MA, Pi Y-L. Numerical modelling of deconstructable composite beams with bolted shear connectors. Numerical Modeling Strategies for Sustainable Concrete Structures, Aix-en-Provence, France, May, II-2, 2012, 1-8.

[2] Bradford MA, Pi Y-L. Numerical modelling of composite steel-concrete beams for life-cycle deconstructability. $1^{\text {st }}$ Intentional Conference on Performance-Based and Life-Cycle Structural Engineering, Hong Kong, December, 2012, $102-$ 109.

[3] Bradford MA. Structural modelling of deconstructable beams fabricated using frictiongrip shear connection. $4^{\text {th }}$ International Conference on Mobile, Adaptable and Rapidly Assembled Structures, Ostend, Belgium, June, 2014.

[4] Ataei A, Bradford MA, Liu X. Experimental study of composite beams having a precast geopolymer concrete slab and deconstructable bolted shear connectors. Engineering Structures 2016;114:1-13.

[5] Ataei A, Bradford MA, Liu X. Flexural performance of innovative sustainable composite steel-concrete beams. Engineering Structures 2017;130:282-296.
[6] Ataei A, Bradford MA, Valipour HR. Experimental study of flush end plate beam-toCFST column composite joints with deconstructable bolted shear connectors. Engineering Structures 2015;99:616-630.

[7] Ataei A, Bradford MA, Valipour HR. Experimental study of sustainable high strength steel flush end plate beam-to-column composite joints with deconstructable bolted shear connectors. Engineering Structures 2016;123: 124-140.

[8] Ataei A, Bradford MA, Valipour HR. Finite element analysis of HSS semi-rigid composite joints with precast concrete slabs and demountable bolted shear connectors. Finite Elements in Analysis and Design 2016;122:1638.

[9] British Standards Institution. Eurocode 3: Design of Steel Structures: Part 1.1 General Rules and Rules for Buildings. BS EN 1993-1-1. London; 2005.

[10] British Standards Institution. Eurocode 4: Design of Composite Steel and Concrete Structures: Part 1.1 General Rules and Rules for Buildings. BS EN 1994-1-1. London; 2005.

[11] Trahair NS, Bradford MA, Nethercot DA, Gardner L. The Behaviour and Design of Steel Structures to EC3. $4^{\text {th }}$ edn. London; 2008.

[12]DR AS/NZS 2327:2016. Composite Structures Composite Steel-Concrete Construction in Buildings. Sydney; 2016.

[13]ABAQUS User's Manual. Version 6.12. Providence, RI; 2012.

[14]Liew JYR, Teo TH, Shanmugam NE, Yu CH. Testing of steel-concrete composite connections and appraisal of results. Journal of Constructional Steel Research 2000;56:117-150.

[15] Anderson D, Najafi AA. Performance of composite connections: major axis end plate joints. Journal of Constructional Steel Research 1994;31:31-57.

[16]Ahmed B, Nethercot DA. Design of flush endplate connections in composite beams. The Structural Engineer 1997;75:233-244. 